\title{
Matkowski theorems in the context of quasi-metric spaces and consequences on $G$-metric spaces
}

\section{Erdal Karapınar, Antonio-Francisco Roldán-López-de-Hierro and Bessem Samet}

\begin{abstract}
In this paper, we prove the characterization of a Matkowski's theorem in the setting of quasi-metric spaces. As a result, we observe that some recent fixed point results in the context of $G$-metric spaces are consequences of our main result.
\end{abstract}

\section{Introduction}

After the appearance of the Banach Contractive Mapping Principle in his thesis in 1922, Fixed Point Theory has become one of the most useful tools in Nonlinear Analysis due, mainly, to its applications. Many results have been introduced in this field throughout the last ninety years.

In [1], Matkowski presented the following result.

Theorem 1.1 (Matkowski [1], Theorem 1). Let $(X, d)$ be a complete metric space, $T: X \rightarrow X, \alpha:[0, \infty)^{5} \rightarrow[0, \infty)$, and let $\gamma(t)=\alpha(t, t, t, 2 t, 2 t)$ for all $t \geq 0$. Suppose that

(1) $\alpha$ is nondecreasing with respect to each variable,

(2) $\lim _{t \rightarrow \infty}(t-\gamma(t))=\infty$,

Key Words: Fixed point, Contractivity condition, Quasi-metric space, $G$-metric space. 2010 Mathematics Subject Classification: Primary 47H10, 54H25; Secondary 47H05, $65 \mathrm{~J} 15$.

Received:29.10.2014

Accepted:07.01.2015 
(3) $\lim _{k \rightarrow \infty} \gamma^{k}(t)=0$ for all $t>0$,

(4) for every $x \in X$, there is a positive integer $n=n(x)$ such that, for all $y \in X$,

$d\left(T^{n(x)} x, T^{n(x)} y\right) \leq \alpha\left(d\left(x, T^{n} x\right), d\left(x, T^{n} y\right), d(x, y), d\left(T^{n} x, y\right), d\left(T^{n} y, y\right)\right)$.

Then $T$ has a unique fixed point $a \in X$ and for each $x \in X, \lim _{k \rightarrow \infty} T^{k} x=a$.

Only considering the function $\gamma:[0, \infty) \rightarrow[0, \infty)$, Matkowski obtained the following consequence.

Corollary 1.1 (Matkowski [1], Theorem 2). Let $(X, d)$ be a complete metric space and let $T: X \rightarrow X$ be a mapping. Assume that there exists a nondecreasing function $\gamma:[0, \infty) \rightarrow[0, \infty)$ such that, for all $t>0$, we have that $\lim _{t \rightarrow \infty}(t-\gamma(t))=\infty$ and $\lim _{k \rightarrow \infty} \gamma^{k}(t)=0$, and verifying that for each $x \in X$, there is a positive integer $n=n(x)$ such that

$$
d\left(T^{n(x)} x, T^{n(x)} y\right) \leq \gamma(d(x, y)) \quad \text { for all } y \in X .
$$

Then $T$ has a unique fixed point $a \in X$. Moreover, for each $x \in X, \lim _{k \rightarrow \infty} T^{k} x=$ $a$.

Very recently, Gajić and Stojaković [2] proved the analog of Matkowski's theorem in the context of $G$-metric spaces as follows. We recall the classification of auxiliary functions given in [2]. Let $\varphi:[0, \infty) \rightarrow[0, \infty)$ be a nondecreasing function. The additional properties that can be imposed on $\varphi$ are listed below:

$\left(\varphi_{1}\right) \varphi(0)=0$

$\left(\varphi_{2}\right) \varphi(t)<t$, for all $t>0$

$\left(\varphi_{3}\right) \lim _{k \rightarrow \infty} \varphi^{k}(t)=0$, for all $t>0$

$\left(\varphi_{4}\right)$ if $\left\{t_{i}\right\} \subset[0, \infty)$ is a sequence such that $t_{i+1} \leq \varphi\left(t_{i}\right)$, then $\lim _{i \rightarrow \infty} t_{i}=0$;

$\left(\varphi_{5}\right)$ for any $y \geq 0$ there exists a $t(y) \geq 0, t(y)=\sup _{t \geq 0}\{t \leq y+\varphi(t)\}$;

$\left(\varphi_{6}\right) \lim _{t \rightarrow \infty}(t-\varphi(t))=\infty$

$\left(\varphi_{7}\right) \sum_{i=1}^{\infty} \varphi^{i}(t)<\infty$, for all $t>0$ 
Theorem 1.2 (Gajić and Stojaković [2], Theorem 2.1). Let $(X, G)$ be a complete $G$-metric space, $T: X \rightarrow X$, and $\varphi:[0, \infty) \rightarrow[0, \infty)$. If $\varphi$ is nondecreasing mapping that satisfies either $\left(\varphi_{3}\right) \&\left(\varphi_{6}\right)$ or $\left(\varphi_{4}\right) \&\left(\varphi_{5}\right)$ and for each $x \in X$ there is a positive integer $n=n(x)$ such that for all $y \in X$,

$$
G\left(T^{n(x)} x, T^{n(x)} x, T^{n(x)} y\right) \leq \varphi(G(x, x, y)),
$$

then $T$ has a unique fixed point $a \in X$. Moreover, for each $x \in X$, $\lim _{k \rightarrow \infty} T^{k}(x)=a$.

In recent times, some authors have proved that many fixed point theorems in the context of $G$-metric spaces can be deduced from existing results in the context of quasi-metric spaces and/or metric spaces (see e.g. [3, 4, 5, 6, 7, 8]). However, in [2], the authors claimed that their results cannot be observed from the corresponding results in the frame of usual metric spaces or quasi metric spaces via the techniques used in $[3,4]$.

This manuscript has two aims: on the one hand, we introduce two different conditions to prove the analog of Matkowski's theorem in the setting of quasi-metric spaces by verbatim; on the other hand, we particularize our main results to the setting of $G$-metric spaces pointing out that Gajic and Stojaković's results can be easily derived from such consequences by using the same techniques in $[3,4]$.

\section{Preliminaries}

Throughout this paper, $\mathbb{N}=\{0,1,2, \ldots\}$ denotes the set of nonnegative integers and $\mathbb{R}$ denotes the set of all real numbers. First, let us recall the following definitions, notations and basic results.

Definition 2.1. A quasi-metric on $X$ is a function $q: X \times X \rightarrow[0, \infty)$ satisfying the following properties:

$\left(q_{1}\right) q(x, y)=0$ if and only if $x=y$;

$\left(q_{2}\right) q(x, y) \leq q(x, z)+q(z, y)$ for any points $x, y, z \in X$.

In such a case, the pair $(X, q)$ is called a quasi-metric space.

It is clear that any metric space is a quasi-metric space, but the converse is not true. Now, we give the notions of convergence and completeness on quasi-metric spaces.

Definition 2.2. Let $(X, q)$ be a quasi-metric space, $\left\{x_{n}\right\}$ be a sequence in $X$, and $x \in X$. We say that: 
- $\left\{x_{n}\right\}$ converges to $x$ (and we denote it by $\left\{x_{n}\right\} \rightarrow x$ ) if

$$
\lim _{n \rightarrow \infty} q\left(x_{n}, x\right)=\lim _{n \rightarrow \infty} q\left(x, x_{n}\right)=0 ;
$$

- $\left\{x_{n}\right\}$ is a Cauchy sequence if for all $\varepsilon>0$, there exists $n_{0} \in \mathbb{N}$ such that $q\left(x_{n}, x_{m}\right)<\varepsilon$ for all $n, m \geq n_{0}$.

The quasi-metric space is said to be complete if every Cauchy sequence is convergent.

As $q$ is not necessarily symmetric, some authors distinguished between left/right Cauchy/convergent sequences and completeness.

Definition 2.3. (Jleli and Samet [4]) Let $(X, q)$ be a quasi-metric space, $\left\{x_{n}\right\}$ be a sequence in $X$, and $x \in X$. We say that:

- $\left\{x_{n}\right\}$ right-converges to $x$ if $\lim _{n \rightarrow \infty} q\left(x_{n}, x\right)=0$;

- $\left\{x_{n}\right\}$ left-converges to $x$ if $\lim _{n \rightarrow \infty} q\left(x, x_{n}\right)=0$;

- $\left\{x_{n}\right\}$ is a right-Cauchy sequence if for all $\varepsilon>0$ there exists $n_{0} \in \mathbb{N}$ such that $q\left(x_{n}, x_{m}\right)<\varepsilon$ for all $m>n \geq n_{0}$;

- $\left\{x_{n}\right\}$ is a left-Cauchy sequence if for all $\varepsilon>0$ there exists $n_{0} \in \mathbb{N}$ such that $q\left(x_{m}, x_{n}\right)<\varepsilon$ for all $m>n \geq n_{0}$.

Remark 2.1. A sequence $\left\{x_{n}\right\}$ in a quasi-metric space is Cauchy if, and only if, it is left-Cauchy and right-Cauchy.

Definition 2.4. Let $(X, q)$ be a quasi-metric space and let $T: X \rightarrow X$ be a mapping. We say that $T$ is

- right-continuous if $\left\{q\left(T x_{n}, T u\right)\right\} \rightarrow 0$ for all sequence $\left\{x_{n}\right\} \subseteq X$ and all $u \in X$ such that $\left\{q\left(x_{n}, u\right)\right\} \rightarrow 0$;

- left-continuous if $\left\{q\left(T u, T x_{n}\right)\right\} \rightarrow 0$ for all sequence $\left\{x_{n}\right\} \subseteq X$ and all $u \in X$ such that $\left\{q\left(u, x_{n}\right)\right\} \rightarrow 0$;

- $T$ is continuous if $\left\{T x_{n}\right\} \rightarrow$ Tu for all sequence $\left\{x_{n}\right\} \subseteq X$ and all $u \in X$ such that $\left\{x_{n}\right\} \rightarrow u$.

Notice that if $T$ is, at the same time, right-continuous and left-continuous, then it is continuous.

With respect to conditions $\left(\varphi_{1}\right)$ to $\left(\varphi_{7}\right)$ introduced in the previous section, Gajić and Stojaković demonstrated the following relationships. 
Lemma 2.1. ([2]) Let $\varphi:[0, \infty) \rightarrow[0, \infty)$ be a nondecreasing function. Then

(i) $\left(\varphi_{3}\right) \Leftrightarrow\left(\varphi_{4}\right) \Rightarrow\left(\varphi_{2}\right)$,

(ii) if $\varphi$ is right continuous, then $\left(\varphi_{2}\right) \Leftrightarrow\left(\varphi_{3}\right) \Leftrightarrow\left(\varphi_{4}\right)$,

(iii) $\left(\varphi_{7}\right) \Rightarrow\left(\varphi_{k}\right) \Rightarrow\left(\varphi_{2}\right) \Rightarrow\left(\varphi_{1}\right)$, where $k \in\{3,4\}$,

(iv) $\left(\varphi_{5}\right) \Leftrightarrow\left(\varphi_{6}\right)$,

$(v)\left(\varphi_{2}\right) \nRightarrow\left(\varphi_{3}\right)$ and $\left(\varphi_{2}\right) \nRightarrow\left(\varphi_{4}\right)$,

(vi) $\left(\varphi_{5}\right)+\left(\varphi_{3}\right) \nRightarrow\left(\varphi_{7}\right)$ and $\left(\varphi_{6}\right)+\left(\varphi_{3}\right) \nRightarrow\left(\varphi_{7}\right)$,

(vii) $\left(\varphi_{7}\right) \nRightarrow\left(\varphi_{5}\right)$ and $\left(\varphi_{7}\right) \nRightarrow\left(\varphi_{6}\right)$.

Corollary 2.1. ([2]) A nondecreasing mapping $\varphi:[0, \infty) \rightarrow[0, \infty)$ verifies $\left(\varphi_{3}\right)$ and $\left(\varphi_{6}\right)$ if, and only if, it satisfies $\left(\varphi_{4}\right)$ and $\left(\varphi_{5}\right)$.

\section{The Matkowski's theorem in the context of quasi-metric spaces}

In this section, we will prove two different analogs of the previous theorem in the context of quasi-metric spaces. To be exact, we will need an additional hypothesis on the contractive condition or in the quasi-metric space.

Let denote by $\mathcal{F}_{\text {Mat }}$ the family of all functions $\varphi:[0, \infty) \rightarrow[0, \infty)$ as in Theorem 1.1, that is, $\varphi$ is nondecreasing and it satisfies $\left(\varphi_{3}\right)$ and $\left(\varphi_{6}\right)$. By Lemma 2.1, we have the following characterization.

Lemma 3.1. (Gajić and Stojaković [2]) A nondecreasing function $\varphi:[0, \infty) \rightarrow$ $[0, \infty)$ belongs to $\mathcal{F}_{\text {Mat }}$ if, and only if, it satisfies $\left(\varphi_{4}\right)$ and $\left(\varphi_{5}\right)$.

In fact, as $\left(\varphi_{3}\right)$ implies $\left(\varphi_{2}\right)$, we also have the following result.

Lemma 3.2. Suppose that $\varphi \in \mathcal{F}_{\text {Mat }}$.

1. $\varphi(t)<t$ for all $t>0$.

2. $\varphi(t) \leq t$ for all $t \geq 0$.

3. $\varphi(0)=0$.

4. $\lim _{k \rightarrow \infty} \varphi^{k}(t)=0$ for all $t \geq 0$.

5. $\varphi^{k}$ is nondecreasing for all $k \in \mathbb{N}$. 


\section{1 $M$-symmetric quasi-metric spaces}

In this subsection, we present a simple condition which will be able to consider an extension of Matkowski's theorem to quasi-metric spaces and to $G$-metric spaces.

Definition 3.1. Given a positive real number $M>0$, we will say that a quasi-metric space $(X, q)$ is $M$-symmetric if

$$
q(y, x) \leq M q(x, y) \quad \text { for all } x, y \in X .
$$

If $X$ is not reduced to a single point, we can find $x, y \in X$ such that $q(x, y)>0$. Therefore, $0<q(x, y) \leq M q(y, x) \leq M^{2} q(x, y)$. Hence, $M \geq 1$.

Example 3.1. Using $M=1$, every metric space is a symmetric space. In fact, a quasi-metric space is a metric space if, and only if, it is 1-symmetric.

Example 3.2. Let $X=\mathbb{R}$ and let define

$$
q(x, y)= \begin{cases}2(x-y), & \text { if } x \geq y, \\ y-x, & \text { if } x<y .\end{cases}
$$

Then $(X, q)$ is a complete 2-symmetric quasi-metric space, but it is not a metric space.

The main properties of $M$-symmetric quasi-metric spaces are listed in the following result.

Lemma 3.3. Let $(X, q)$ be an $M$-symmetric quasi-metric space, let $\left\{x_{n}\right\} \subseteq X$ be a sequence and let $x \in X$. Then the following properties hold.

1. The following conditions are equivalent.

(a) $\left\{x_{n}\right\}$ right-converges to $x$.

(b) $\left\{x_{n}\right\}$ left-converges to $x$.

(c) $\left\{x_{n}\right\}$ converges to $x$.

2. If a sequence is right-convergent, then it is convergent, and its limit coincide with its right-limit.

3. The following conditions are equivalent.

(a) $\left\{x_{n}\right\}$ is right-Cauchy.

(b) $\left\{x_{n}\right\}$ is left-Cauchy.

(c) $\left\{x_{n}\right\}$ is Cauchy.

4. If $\left\{y_{n}\right\} \subseteq X$ and $\left\{q\left(x_{n}, y_{n}\right)\right\} \rightarrow 0$, then $\left\{q\left(y_{n}, x_{n}\right)\right\} \rightarrow 0$. 


\subsection{The Matkowski's theorem on $M$-symmetric quasi-metric spaces}

In this subsection, we prove a version of Theorem 1.1 using the $M$-symmetry of the quasi-metric space.

Definition 3.2. Given $M \geq 1$ and two functions $\alpha:[0, \infty)^{5} \rightarrow[0, \infty)$ and $\gamma:[0, \infty) \rightarrow[0, \infty)$, we will say that $(\alpha, \gamma, M)$ is a Matkowski's triple if the following conditions are fulfilled:

$\left(\mathcal{P}_{1}\right) \alpha$ is nondecreasing with respect to each variable and $\gamma$ is nondecreasing;

$\left(\mathcal{P}_{2}\right) \alpha(t, t, t,(M+1) t,(M+1) t) \leq \gamma(t)$ for all $t \geq 0$;

$\left(\mathcal{P}_{3}\right) \lim _{t \rightarrow \infty}(t-\gamma(t))=\infty$;

$\left(\mathcal{P}_{4}\right) \lim _{k \rightarrow \infty} \gamma^{k}(t)=0$ for all $t>0$.

Notice that if $(\alpha, \gamma, M)$ is a Matkowski's triple, then $\gamma \in \mathcal{F}_{\text {Mat }}$, and all items of Lemma 3.2 are applicable.

Example 3.3. Suppose that, given $M \geq 1$ and $\lambda \in[0,1), \alpha$ and $\gamma$ are defined by

$$
\begin{aligned}
& \alpha\left(t_{1}, t_{2}, t_{3}, t_{4}, t_{5}\right)=\lambda \max \left\{t_{1}, t_{2}, t_{3}, \frac{t_{4}}{M+1}, \frac{t_{5}}{M+1}\right\}, \\
& \gamma(t)=\alpha(t, t, t,(M+1) t,(M+1) t)=\lambda t .
\end{aligned}
$$

Then $(\alpha, \gamma, M)$ is a Matkowski's triple.

The following one is the main result of the present manuscript.

Theorem 3.1. Let $(X, q)$ be a complete $M$-symmetric quasi-metric space and let $T: X \rightarrow X$ be a mapping. Suppose that there exists a Matkowski's triple $(\alpha, \gamma, M)$ verifying the following property:

- for every $x \in X$, there is a positive integer $n=n(x)$ such that, for all $y \in X$,

$$
\begin{aligned}
q\left(T^{n(x)} x, T^{n(x)} y\right) \leq \alpha & \left(q(x, y), q\left(x, T^{n(x)} x\right),\right. \\
& \left.q\left(x, T^{n(x)} y\right), q\left(T^{n(x)} x, y\right), q\left(T^{n(x)} y, y\right)\right) .
\end{aligned}
$$

Then $T$ has a unique fixed point $a \in X$. Furthermore, for each $x \in X$, $\lim _{k \rightarrow \infty} T^{k} x=a$ and $T^{n(a)}$ is continuous at $a$. 
Remark 3.1. Notice that the mapping $T$ is not assumed to be continuous.

The previous theorem improves Theorem 1.1 in three senses: (1) we only assume that $(X, q)$ is a quasi-metric space; (2) we only suppose that $\alpha(t, t, t,(M+1) t,(M+1) t) \leq \gamma(t)$ for all $t \geq 0$, but the equality is not necessary; (3) we also prove that $T^{n(a)}$ is continuous at $a$.

Our proof is based on the original Matkowski's proof given in [1]. However, some details are different. Then, for a better understanding, we divide the proof in 14 steps.

Proof. Step 1. We claim that, for all $x \in X$, the set $\left\{q\left(x, T^{k} x\right): k \in \mathbb{N}\right\}$ is bounded.

Let $x \in X$ be arbitrary. By hypothesis, there exists a positive integer $n=n(x)$ such that (3) holds. Given an integer $s \in\{0,1,2, \ldots, n(x)-1\}$, we are going to show that the set $\left\{q\left(x, T^{k n(x)+s} x\right): k \in \mathbb{N}\right\}$ is bounded (varying $s$ on $\{0,1,2, \ldots, n(x)-1\}$, we can conclude that Step 1 holds). We define

$$
\begin{aligned}
& u_{k}=q\left(x, T^{k n(x)+s} x\right) \quad \text { for all } k \in\{0,1,2, \ldots\}, \\
& h=\max \left\{u_{0}, q\left(x, T^{n(x)}\right)\right\} .
\end{aligned}
$$

Due to $\left(\varphi_{6}\right)$, there exists $c \in(0, \infty)$, with $c>h$, such that

$$
t-\varphi(t)>h \text { for all } t \in[c, \infty) .
$$

Since $c>h \geq u_{0}$, then

$$
u_{0}<c .
$$

Next, we claim that $u_{k}<c$ for all $k \in \mathbb{N}$. On the contrary, assume that there exists a positive integer $j$ such that $u_{j} \geq c$ but $u_{i}<c$ for all $i<j$. Notice that $u_{j-1}<c \leq u_{j}$. Taking (3) into account together with the triangle inequality, we derive that

$$
\begin{aligned}
u_{j} & =q\left(x, T^{j n(x)+s} x\right) \leq q\left(x, T^{n(x)} x\right)+q\left(T^{n(x)} x, T^{j n(x)+s} x\right) \\
& \leq h+q\left(T^{n(x)} x, T^{n(x)} T^{(j-1) n(x)+s} x\right) .
\end{aligned}
$$


Using the contractivity condition (3) with $y=T^{(j-1) n(x)+s} x$,

$$
\begin{aligned}
q\left(T^{n(x)} x, T^{n(x)} T^{(j-1) n(x)+s} x\right) \\
\leq \alpha\left(q\left(x, T^{(j-1) n(x)+s} x\right), q\left(x, T^{n(x)} x\right), q\left(x, T^{n(x)} T^{(j-1) n(x)+s} x\right),\right. \\
\left.\quad q\left(T^{n(x)} x, T^{(j-1) n(x)+s} x\right), q\left(T^{n(x)} T^{(j-1) n(x)+s} x, T^{(j-1) n(x)+s} x\right)\right) \\
=\alpha\left(u_{j-1}, q\left(x, T^{n(x)} x\right), q\left(x, T^{j n(x)+s} x\right), q\left(T^{n(x)} x, T^{(j-1) n(x)+s} x\right),\right. \\
\left.\quad q\left(T^{j n(x)+s} x, T^{(j-1) n(x)+s} x\right)\right) \\
\leq \alpha\left(u_{j-1}, h, u_{j}, q\left(T^{n(x)} x, T^{(j-1) n(x)+s} x\right), q\left(T^{j n(x)+s} x, T^{(j-1) n(x)+s} x\right)\right) .
\end{aligned}
$$

Notice that

$$
\begin{aligned}
& q\left(T^{n(x)} x, T^{(j-1) n(x)+s} x\right) \leq q\left(T^{n(x)} x, x\right)+q\left(x, T^{(j-1) n(x)+s} x\right) \\
& \quad \leq M q\left(x, T^{n(x)} x\right)+q\left(x, T^{(j-1) n(x)+s} x\right) \\
& \quad \leq M h+u_{j-1} \leq M c+c \leq(M+1) u_{j},
\end{aligned}
$$

and

$$
\begin{aligned}
& q\left(T^{j n(x)+s} x, T^{(j-1) n(x)+s} x\right) \leq q\left(T^{j n(x)+s} x, x\right)+q\left(x, T^{(j-1) n(x)+s} x\right) \\
& \quad \leq M q\left(x, T^{j n(x)+s} x\right)+q\left(x, T^{(j-1) n(x)+s} x\right)=M u_{j}+u_{j-1} \leq(M+1) u_{j} .
\end{aligned}
$$

As $\alpha$ is nondecreasing on each variable, it follows from (6) that

$$
\begin{aligned}
& q\left(T^{n(x)} x, T^{n(x)} T^{(j-1) n(x)+s} x\right) \\
& \quad \leq \alpha\left(u_{j-1}, h, u_{j}, q\left(T^{n(x)} x, T^{(j-1) n(x)+s} x\right), q\left(T^{j n(x)+s} x, T^{(j-1) n(x)+s} x\right)\right) \\
& \quad \leq \alpha\left(u_{j}, u_{j}, u_{j},(M+1) u_{j},(M+1) u_{j}\right) \leq \gamma\left(u_{j}\right) .
\end{aligned}
$$

Then (5) implies that

$$
u_{j} \leq h+q\left(T^{n(x)} x, T^{n(x)} T^{(j-1) n(x)+s} x\right) \leq h+\gamma\left(u_{j}\right)
$$

Therefore, $u_{j}-\gamma\left(u_{j}\right) \leq h$, which contradicts (4) because we suppose that $u_{j} \geq c$. Therefore, it is impossible to find such $j$, which proves that

$$
q\left(x, T^{k n(x)+s} x\right)=u_{k}<c \quad \text { for all } k \in\{0,1,2, \ldots\} .
$$

This proves that the set $\left\{q\left(x, T^{k n(x)+s} x\right): k \in \mathbb{N}\right\}$ is bounded, and varying $s$ on $\{0,1,2, \ldots, n(x)-1\}$, we conclude that Step 1 holds. Let define

$$
S_{x}^{1}=\sup \left\{q\left(x, T^{k} x\right): k \in\{0,1,2, \ldots\}\right\} .
$$


Step 2. We claim that, for all $x \in X$, the set $\left\{q\left(T^{k} x, x\right): k \in \mathbb{N}\right\}$ is bounded.

This step follows from the fact that $q\left(T^{k} x, x\right) \leq M q\left(x, T^{k} x\right) \leq M \cdot S_{x}^{1}$ for all $x \in X$ and all $k \in \mathbb{N}$. Let define, for all $x \in X$,

$$
S_{x}^{2}=\sup \left\{q\left(T^{k} x, x\right): k \in\{0,1,2, \ldots\}\right\} \quad \text { and } \quad S_{x}=S_{x}^{1}+S_{x}^{2} .
$$

As a consequence of Steps 1 and 2, we have proved that, for all $x \in X$, the orbit $\left\{T^{k} x: k \in \mathbb{N}\right\}$ is a $q$-bounded subset of $X$ because

$$
q\left(T^{k} x, T^{k^{\prime}} x\right) \leq q\left(T^{k} x, x\right)+q\left(x, T^{k^{\prime}} x\right) \leq S_{x}^{1}+S_{x}^{2}=S_{x} \quad \text { for all } k, k^{\prime} \in \mathbb{N} .
$$

If $x$ is a fixed point of $T$, then the existence of such kind of points is proved. On the contrary case, if $T x \neq x$, then

$$
S_{x}^{1} \geq q(x, T x)>0 \quad \text { and } \quad S_{x}^{2} \geq q(T x, x)>0 .
$$

The following steps have sense when we begin the process using a point $x_{0} \in X$ which is not a fixed point of $T$.

Step 3. Starting from an arbitrary point $x_{0} \in X$, we claim that the iterative sequence $\left\{x_{k}\right\}_{k \geq 0}$ given by

$$
x_{k+1}=T^{n_{k}} x_{k} \quad \text { for all } k \in \mathbb{N} \quad\left(\text { where } n_{k}=n\left(x_{k}\right)\right)
$$

verifies the following properties

$$
\begin{aligned}
& x_{k+1}=T^{n_{0}+n_{1}+\ldots+n_{k}} x_{0}, \\
& x_{k+j}=T^{n_{k}+n_{k+1}+\ldots+n_{k+j-1}} x_{k} \quad \text { for all } k, j \in \mathbb{N} .
\end{aligned}
$$

Indeed, notice that

$$
x_{1}=T^{n_{0}} x_{0}, \quad x_{2}=T^{n_{1}} x_{1}=T^{n_{1}} T^{n_{0}} x_{0}=T^{n_{0}+n_{1}} x_{0},
$$

and, by induction methodology, we deduce that (10) holds. This means that $\left\{x_{k}\right\}_{k \geq 0}$ is a subsequence of the orbit $\left\{T^{k} x_{0}\right\}_{k=0}^{\infty}$. To prove (11), we observe that

$$
\begin{aligned}
x_{k+j} & =T^{n_{0}+n_{1}+\ldots+n_{k+j-1}} x_{0}=T^{n_{k}+n_{k+1}+\ldots+n_{k+j-1}}\left(T^{n_{0}+n_{1}+\ldots+n_{k-1}} x_{0}\right) \\
& =T^{n_{k}+n_{k+1}+\ldots+n_{k+j-1}} x_{k} .
\end{aligned}
$$

Step 4. We claim that $\left\{x_{k}\right\}_{k \geq 0}$ is a right-Cauchy sequence on $(X, q)$. 
If $T x_{0}=x_{0}$, then $x_{0}$ is a fixed point of $T$ (and the existence of such kind of points is guaranteed). Assume that $T x_{0} \neq x_{0}$. Let $\varepsilon>0$ be arbitrary. By $\left(\mathcal{P}_{4}\right), \lim _{k \rightarrow \infty} \gamma^{k}\left(S_{x_{0}}^{1}\right)=0$. Hence, there exists $k_{0} \in \mathbb{N}$ such that

$$
\gamma^{k}\left(S_{x_{0}}^{1}\right)<\varepsilon \quad \text { for all } k \geq k_{0} .
$$

Let $k, j \in \mathbb{N}$ be arbitrary integers such that $k \geq k_{0}$ and $j \geq 1$. Denote by $s_{0}$ the integer $s_{0}=n_{k}+n_{k+1}+\ldots+n_{k+j-1}$ and let $s_{1} \in\left\{s_{0}, n_{k-1}, s_{0}+n_{k-1}\right\}$ be the appropriate index such that

$$
\begin{aligned}
\max & \left\{q\left(x_{k-1}, T^{s_{0}} x_{k-1}\right), q\left(x_{k-1}, T^{n_{k-1}} x_{k-1}\right), q\left(x_{k-1}, T^{s_{0}+n_{k-1}} x_{k-1}\right)\right\} \\
& =q\left(x_{k-1}, T^{s_{1}} x_{k-1}\right) .
\end{aligned}
$$

By using (10) and (11), we get that

$$
\begin{aligned}
q\left(x_{k}, x_{k+j}\right) & =q\left(T^{n_{k-1}} x_{k-1}, T^{n_{k-1}+n_{k}+n_{k+1}+\ldots+n_{k+j-1}} x_{k-1}\right) \\
& =q\left(T^{n_{k-1}} x_{k-1}, T^{n_{k-1}} T^{n_{k}+n_{k+1}+\ldots+n_{k+j-1}} x_{k-1}\right) \\
& =q\left(T^{n_{k-1}} x_{k-1}, T^{n_{k-1}} T^{s_{0}} x_{k-1}\right) .
\end{aligned}
$$

Using the contractivity condition (3) with $y=T^{s_{0}} x_{k-1}$, we observe that

$$
\begin{gathered}
q\left(x_{k}, x_{k+j}\right)=q\left(T^{n_{k-1}} x_{k-1}, T^{n_{k-1}} T^{s_{0}} x_{k-1}\right) \\
\leq \alpha\left(q\left(x_{k-1}, T^{s_{0}} x_{k-1}\right), q\left(x_{k-1}, T^{n\left(x_{k-1}\right)} x_{k-1}\right), q\left(x_{k-1}, T^{n\left(x_{k-1}\right)} T^{s_{0}} x_{k-1}\right),\right. \\
\left.q\left(T^{n\left(x_{k-1}\right)} x_{k-1}, T^{s_{0}} x_{k-1}\right), q\left(T^{n\left(x_{k-1}\right)} T^{s_{0}} x_{k-1}, T^{s_{0}} x_{k-1}\right)\right) \\
\leq \alpha\left(q\left(x_{k-1}, T^{s_{0}} x_{k-1}\right), q\left(x_{k-1}, T^{n_{k-1}} x_{k-1}\right), q\left(x_{k-1}, T^{s_{0}+n_{k-1}} x_{k-1}\right),\right. \\
\left.q\left(T^{n_{k-1}} x_{k-1}, T^{s_{0}} x_{k-1}\right), q\left(T^{n_{k-1}+s_{0}} x_{k-1}, T^{s_{0}} x_{k-1}\right)\right) .
\end{gathered}
$$

Taking into account (13), we observe that

$$
\begin{aligned}
& q\left(T^{n_{k-1}} x_{k-1}, T^{s_{0}} x_{k-1}\right) \leq q\left(T^{n_{k-1}} x_{k-1}, x_{k-1}\right)+q\left(x_{k-1}, T^{s_{0}} x_{k-1}\right) \\
& \quad \leq M q\left(x_{k-1}, T^{n_{k-1}} x_{k-1}\right)+q\left(x_{k-1}, T^{s_{0}} x_{k-1}\right) \leq(M+1) q\left(x_{k-1}, T^{s_{1}} x_{k-1}\right)
\end{aligned}
$$

and

$$
\begin{aligned}
& q\left(T^{n_{k-1}+s_{0}} x_{k-1}, T^{s_{0}} x_{k-1}\right) \leq q\left(T^{n_{k-1}+s_{0}} x_{k-1}, x_{k-1}\right)+q\left(x_{k-1}, T^{s_{0}} x_{k-1}\right) \\
& \quad \leq M q\left(x_{k-1}, T^{n_{k-1}+s_{0}} x_{k-1}\right)+q\left(x_{k-1}, T^{s_{0}} x_{k-1}\right) \\
& \quad \leq(M+1) q\left(x_{k-1}, T^{s_{1}} x_{k-1}\right) .
\end{aligned}
$$


As $\alpha$ is nondecreasing on each argument, it follows from (14) that

$$
\begin{aligned}
q\left(x_{k}, x_{k+j}\right) & \leq \alpha\left(q\left(x_{k-1}, T^{s_{0}} x_{k-1}\right), q\left(x_{k-1}, T^{n_{k-1}} x_{k-1}\right), q\left(x_{k-1}, T^{s_{0}+n_{k-1}} x_{k-1}\right),\right. \\
& \left.q\left(T^{n_{k-1}} x_{k-1}, T^{s_{0}} x_{k-1}\right), q\left(T^{n_{k-1}+s_{0}} x_{k-1}, T^{s_{0}} x_{k-1}\right)\right) \\
& \leq \alpha\left(q\left(x_{k-1}, T^{s_{1}} x_{k-1}\right), q\left(x_{k-1}, T^{s_{1}} x_{k-1}\right), q\left(x_{k-1}, T^{s_{1}} x_{k-1}\right),\right. \\
& \left.(M+1) q\left(x_{k-1}, T^{s_{1}} x_{k-1}\right),(M+1) q\left(x_{k-1}, T^{s_{1}} x_{k-1}\right)\right) \\
& \leq \gamma\left(q\left(x_{k-1}, T^{s_{1}} x_{k-1}\right)\right) .
\end{aligned}
$$

Using $s_{2} \in\left\{s_{1}, n_{k-2}, s_{1}+n_{k-2}\right\}$ be the appropriate index such that

$$
\begin{aligned}
\max & \left\{q\left(x_{k-2}, T^{s_{1}} x_{k-2}\right), q\left(x_{k-2}, T^{n_{k-2}} x_{k-2}\right), q\left(x_{k-2}, T^{s_{1}+n_{k-2}} x_{k-2}\right)\right\} \\
& =q\left(x_{k-2}, T^{s_{2}} x_{k-2}\right),
\end{aligned}
$$

and repeating the previous argument, we deduce that

$$
q\left(x_{k-1}, T^{s_{1}} x_{k-1}\right) \leq \gamma\left(q\left(x_{k-2}, T^{s_{2}} x_{k-2}\right)\right) .
$$

Hence, as $\gamma$ is nondecreasing, we have that

$$
\begin{aligned}
q\left(x_{k}, x_{k+j}\right) & \leq \gamma\left(q\left(x_{k-1}, T^{s_{1}} x_{k-1}\right)\right) \leq \gamma^{2}\left(q\left(x_{k-2}, T^{s_{2}} x_{k-2}\right)\right) \\
& \leq \ldots \leq \gamma^{k}\left(q\left(x_{0}, T^{s_{k}} x_{0}\right)\right)
\end{aligned}
$$

for appropriate indices $s_{0}, s_{1}, \ldots, s_{k} \in \mathbb{N}$. Since $q\left(x_{0}, T^{s_{k}} x_{0}\right) \leq S_{x_{0}}^{1}$ and $\gamma^{k}$ is nondecreasing, if we take $k \geq k_{0}$, it follows from (12) that

$$
q\left(x_{k}, x_{k+j}\right) \leq \gamma^{k}\left(q\left(x_{0}, T^{s_{k}} x_{0}\right)\right) \leq \gamma^{k}\left(S_{x_{0}}^{1}\right)<\varepsilon .
$$

As $k \geq k_{0}$ and $j \geq 1$ are arbitrary, we conclude that $\left\{x_{k}\right\}_{k \geq 0}$ is a right-Cauchy sequence on $(X, q)$.

Step 5. We claim that $\left\{x_{k}\right\}_{k \geq 0}$ is a left-Cauchy sequence on $(X, q)$.

This step follows from Step 4 and item 3 of Lemma 3.3.

Step 6. $\left\{x_{k}\right\}_{k \geq 0}$ converges to some $a \in X$.

Since $\left\{x_{k}\right\}_{k \geq 0}$ is both left- and right-Cauchy, Remark 2.1 guarantees that it is a Cauchy sequence on $(X, q)$. As it is complete, there exists $a \in X$ such that $\left\{x_{k}\right\} \rightarrow a$, which means that

$$
\lim _{k \rightarrow \infty} q\left(a, x_{k}\right)=\lim _{k \rightarrow \infty} q\left(x_{k}, a\right)=0 .
$$

Step 7. We claim that

$$
\lim _{k \rightarrow \infty} q\left(x_{k}, T^{n(a)} x_{k}\right)=0 .
$$


Indeed, using the contractivity condition (3), we have that, for all $k \geq 1$,

$$
\begin{gathered}
q\left(x_{k}, T^{n(a)} x_{k}\right)=q\left(T^{n_{k-1}} x_{k-1}, T^{n(a)} T^{n_{k-1}} x_{k-1}\right)=q\left(T^{n_{k-1}} x_{k-1}, T^{n_{k-1}} T^{n(a)} x_{k-1}\right) \\
\leq \alpha\left(q\left(x_{k-1}, T^{n(a)} x_{k-1}\right), q\left(x_{k-1}, T^{n\left(x_{k-1}\right)} x_{k-1}\right), q\left(x_{k-1}, T^{n\left(x_{k-1}\right)} T^{n(a)} x_{k-1}\right),\right. \\
\left.q\left(T^{n\left(x_{k-1}\right)} x_{k-1}, T^{n(a)} x_{k-1}\right), q\left(T^{n\left(x_{k-1}\right)} T^{n(a)} x_{k-1}, T^{n(a)} x_{k-1}\right)\right) \\
=\alpha\left(q\left(x_{k-1}, T^{n(a)} x_{k-1}\right), q\left(x_{k-1}, T^{n_{k-1}} x_{k-1}\right), q\left(x_{k-1}, T^{n_{k-1}+n(a)} x_{k-1}\right),\right. \\
\left.q\left(T^{n_{k-1}} x_{k-1}, T^{n(a)} x_{k-1}\right), q\left(T^{n_{k-1}+n(a)} x_{k-1}, T^{n(a)} x_{k-1}\right)\right) .
\end{gathered}
$$

Let $r_{1} \in\left\{n(a), n_{k-1}, n_{k-1}+n(a)\right\}$ be an appropriate index such that

$$
\begin{aligned}
\max & \left\{q\left(x_{k-1}, T^{n(a)} x_{k-1}\right), q\left(x_{k-1}, T^{n_{k-1}} x_{k-1}\right), q\left(x_{k-1}, T^{n(a)+n_{k-1}} x_{k-1}\right)\right\} \\
& =q\left(x_{k-1}, T^{r_{1}} x_{k-1}\right) .
\end{aligned}
$$

Since

$$
\begin{aligned}
& q\left(T^{n_{k-1}} x_{k-1}, T^{n(a)} x_{k-1}\right) \leq q\left(T^{n_{k-1}} x_{k-1}, x_{k-1}\right)+q\left(x_{k-1}, T^{n(a)} x_{k-1}\right) \\
& \quad \leq M q\left(x_{k-1}, T^{n_{k-1}} x_{k-1}\right)+q\left(x_{k-1}, T^{n(a)} x_{k-1}\right) \leq(M+1) q\left(x_{k-1}, T^{r_{1}} x_{k-1}\right),
\end{aligned}
$$

and

$$
\begin{aligned}
& q\left(T^{n_{k-1}+n(a)} x_{k-1}, T^{n(a)} x_{k-1}\right) \\
& \quad \leq q\left(T^{n_{k-1}+n(a)} x_{k-1}, x_{k-1}\right)+q\left(x_{k-1}, T^{n(a)} x_{k-1}\right) \\
& \quad \leq M q\left(x_{k-1}, T^{n_{k-1}+n(a)} x_{k-1}\right)+q\left(x_{k-1}, T^{n(a)} x_{k-1}\right) \\
& \quad \leq(M+1) q\left(x_{k-1}, T^{r_{1}} x_{k-1}\right)
\end{aligned}
$$

then it follows from (16) that

$$
\begin{aligned}
& q\left(x_{k}, T^{n(a)} x_{k}\right) \leq \alpha\left(q\left(x_{k-1}, T^{n(a)} x_{k-1}\right), q\left(x_{k-1}, T^{n_{k-1}} x_{k-1}\right), q\left(x_{k-1}, T^{n_{k-1}+n(a)} x_{k-1}\right),\right. \\
&\left.q\left(T^{n_{k-1}} x_{k-1}, T^{n(a)} x_{k-1}\right), q\left(T^{n_{k-1}+n(a)} x_{k-1}, T^{n(a)} x_{k-1}\right)\right) \\
& \leq \alpha\left(q\left(x_{k-1}, T^{r_{1}} x_{k-1}\right), q\left(x_{k-1}, T^{r_{1}} x_{k-1}\right), q\left(x_{k-1}, T^{r_{1}} x_{k-1}\right),\right. \\
&\left.\quad(M+1) q\left(x_{k-1}, T^{r_{1}} x_{k-1}\right),(M+1) q\left(x_{k-1}, T^{r_{1}} x_{k-1}\right)\right) \\
& \leq \\
& \leq\left(q\left(x_{k-1}, T^{r_{1}} x_{k-1}\right)\right) .
\end{aligned}
$$

Repeating this argument and taking into account that $\gamma$ is nondecreasing, it yields that, for all $k \in \mathbb{N}$,

$$
\begin{aligned}
q\left(x_{k}, T^{n(a)} x_{k}\right) & \leq \gamma\left(q\left(x_{k-1}, T^{r_{1}} x_{k-1}\right)\right) \leq \gamma^{2}\left(q\left(x_{k-2}, T^{r_{2}} x_{k-2}\right)\right) \leq \ldots \\
& \leq \gamma^{k}\left(q\left(x_{0}, T^{r_{k}} x_{0}\right)\right) \leq \gamma^{k}\left(S_{x_{0}}^{1}\right) .
\end{aligned}
$$

By using $\left(\mathcal{P}_{4}\right)$, we conclude that Step 7 holds. 
Step 8. We claim that

$$
\lim _{k \rightarrow \infty} q\left(T^{n(a)} x_{k}, x_{k}\right)=0 .
$$

This step follows from Step 7 and from item 4 of Lemma 3.3.

Step 9. We claim that $T^{n(a)} a=a$, that is, a is a fixed point of $T^{n(a)}$.

We reason by contradiction. Assume that $T^{n(a)} a \neq a$ and let

$$
\varepsilon_{1}=q\left(a, T^{n(a)} a\right)>0 \quad \text { and } \quad \varepsilon_{2}=q\left(T^{n(a)} a, a\right)>0 .
$$

Without loss of generality, suppose that $\varepsilon_{1} \leq \varepsilon_{2}$ (the contrary case is similar). By item 1 of Lemma 3.2,

$$
\gamma\left(\varepsilon_{1}\right)<\varepsilon_{1} .
$$

Let $k_{0} \in \mathbb{N}$ be such that

$$
\begin{aligned}
\max & \left\{q\left(a, x_{k}\right), q\left(x_{k}, a\right), q\left(T^{n(a)} x_{k}, x_{k}\right), q\left(x_{k}, T^{n(a)} x_{k}\right)\right\} \\
& \leq \frac{\varepsilon_{1}-\gamma\left(\varepsilon_{1}\right)}{4}<\varepsilon_{1} \quad \text { for all } k \geq k_{0} .
\end{aligned}
$$

By using the triangle inequality,

$$
\begin{aligned}
\varepsilon_{2} & =q\left(T^{n(a)} a, a\right) \leq q\left(T^{n(a)} a, T^{n(a)} x_{k}\right)+q\left(T^{n(a)} x_{k}, x_{k}\right)+q\left(x_{k}, a\right) \\
& \leq q\left(T^{n(a)} a, T^{n(a)} x_{k}\right)+\frac{\varepsilon_{1}-\gamma\left(\varepsilon_{1}\right)}{2} .
\end{aligned}
$$

Since

$q\left(T^{n(a)} a, x_{k}\right) \leq q\left(T^{n(a)} a, a\right)+q\left(a, x_{k}\right) \leq M q\left(a, T^{n(a)} a\right)+q\left(a, x_{k}\right) \leq(M+1) \varepsilon_{1}$

and

$$
\begin{aligned}
& q\left(a, T^{n(a)} x_{k}\right) \leq q\left(a, x_{k}\right)+q\left(x_{k}, T^{n(a)} x_{k}\right) \\
& \quad \leq \frac{\varepsilon_{1}-\gamma\left(\varepsilon_{1}\right)}{4}+\frac{\varepsilon_{1}-\gamma\left(\varepsilon_{1}\right)}{4}=\frac{\varepsilon_{1}-\gamma\left(\varepsilon_{1}\right)}{2}<\varepsilon_{1},
\end{aligned}
$$

the contractivity condition (3) guarantees that

$$
\begin{aligned}
& q\left(T^{n(a)} a, T^{n(a)} x_{k}\right) \\
& \quad \leq \alpha\left(q\left(a, x_{k}\right), q\left(a, T^{n(a)} a\right), q\left(a, T^{n(a)} x_{k}\right), q\left(T^{n(a)} a, x_{k}\right), q\left(T^{n(a)} x_{k}, x_{k}\right)\right) \\
& \quad \leq \alpha\left(\varepsilon_{1}, \varepsilon_{1}, \varepsilon_{1},(M+1) \varepsilon_{1}, \varepsilon_{1}\right) \leq \alpha\left(\varepsilon_{1}, \varepsilon_{1}, \varepsilon_{1},(M+1) \varepsilon_{1},(M+1) \varepsilon_{1}\right) \\
& \quad \leq \gamma\left(\varepsilon_{1}\right) .
\end{aligned}
$$


From (18), it yields

$$
\begin{aligned}
\varepsilon_{2} & \leq q\left(T^{n(a)} a, T^{n(a)} x_{k}\right)+\frac{\varepsilon_{1}-\gamma\left(\varepsilon_{1}\right)}{2} \\
& \leq \gamma\left(\varepsilon_{1}\right)+\frac{\varepsilon_{1}-\gamma\left(\varepsilon_{1}\right)}{2}=\frac{\varepsilon_{1}+\gamma\left(\varepsilon_{1}\right)}{2}<\frac{\varepsilon_{1}+\varepsilon_{1}}{2}=\varepsilon_{1} \leq \varepsilon_{2},
\end{aligned}
$$

which is a contradiction. As a consequence, $T^{n(a)} a=a$.

Step 10. We claim that a is the unique fixed point of $T^{n(a)}$.

Suppose, on the contrary, that there exists $b \in X$, with $b \neq a$, such that $T^{n(a)} b=b$. Taking (3) into account, we get that

$$
\begin{aligned}
q(a, b) & =q\left(T^{n(a)} a, T^{n(a)} b\right) \\
& \leq \alpha\left(q(a, b), q\left(a, T^{n(a)} a\right), q\left(a, T^{n(a)} b\right), q\left(T^{n(a)} a, b\right), q\left(T^{n(a)} b, b\right)\right) \\
& =\alpha(q(a, b), q(a, a), q(a, b), q(a, b), q(b, b))=\alpha(q(a, b), 0, q(a, b), q(a, b), 0) \\
& \leq \alpha(q(a, b), q(a, b), q(a, b),(M+1) q(a, b),(M+1) q(a, b)) \\
& \leq \gamma(q(a, b))<q(a, b),
\end{aligned}
$$

which is a contradiction. Hence, $a$ is the unique fixed point of $T^{n(a)}$.

Step 11. We claim that a is a fixed point of $T$.

By step $9, T^{n(a)}(T a)=T\left(T^{n(a)} a\right)=T a$, which means that $T a$ is also a fixed point of $T^{n(a)}$. And by Step 10, Ta=a.

Step 12. We claim that, for each $x \in X$, we have that $\lim _{k \rightarrow \infty} q\left(a, T^{k} x\right)=0$.

For this purpose, we fix $x \in X$ and let $s \in\{0,1,2, \ldots, n(a)-1\}$ be arbitrary. Let define

$$
b_{k}=q\left(a, T^{k n(a)+s} x\right) \text { for all } k=\{0,1,2, \ldots\} .
$$

Let show that $b_{k} \leq b_{k-1}$ for all $k \geq 1$ reasoning by contradiction. Assume that there exists some $k_{0} \in \mathbb{N}$ such that $b_{k_{0}}>b_{k_{0}-1}$. Therefore,

$$
\begin{aligned}
b_{k_{0}}= & q\left(a, T^{k_{0} n(a)+s} x\right)=q\left(T^{n(a)} a, T^{n(a)} T^{\left(k_{0}-1\right) n(a)+s} x\right) \\
\leq & \alpha\left(q\left(a, T^{\left(k_{0}-1\right) n(a)+s} x\right), q\left(a, T^{n(a)} a\right), q\left(a, T^{n(a)} T^{\left(k_{0}-1\right) n(a)+s} x\right),\right. \\
& \left.\quad q\left(T^{n(a)} a, T^{\left(k_{0}-1\right) n(a)+s} x\right), q\left(T^{n(a)} T^{\left(k_{0}-1\right) n(a)+s} x, T^{\left(k_{0}-1\right) n(a)+s} x\right)\right) \\
\leq & \alpha\left(b_{k_{0}-1}, 0, q\left(a, T^{k_{0} n(a)+s} x\right),\right. \\
& \left.\quad q\left(a, T^{\left(k_{0}-1\right) n(a)+s} x\right), q\left(T^{k_{0} n(a)+s} x, T^{\left(k_{0}-1\right) n(a)+s} x\right)\right) \\
= & \alpha\left(b_{k_{0}-1}, 0, b_{k_{0}}, b_{k_{0}-1}, q\left(T^{k_{0} n(a)+s} x, T^{\left(k_{0}-1\right) n(a)+s} x\right)\right) .
\end{aligned}
$$


Since

$$
\begin{aligned}
& q\left(T^{k_{0} n(a)+s} x, T^{\left(k_{0}-1\right) n(a)+s} x\right) \leq q\left(T^{k_{0} n(a)+s} x, a\right)+q\left(a, T^{\left(k_{0}-1\right) n(a)+s} x\right) \\
& \quad \leq M q\left(a, T^{k_{0} n(a)+s} x\right)+q\left(a, T^{\left(k_{0}-1\right) n(a)+s} x\right)=M b_{k_{0}}+b_{k_{0}-1} \\
& \quad \leq(M+1) b_{k_{0}},
\end{aligned}
$$

taking into account that $b_{k_{0}}>b_{k_{0}-1} \geq 0$, it follows that

$$
\begin{aligned}
b_{k_{0}} & \leq \alpha\left(b_{k_{0}-1}, 0, b_{k_{0}}, b_{k_{0}-1}, q\left(T^{k_{0} n(a)+s} x, T^{\left(k_{0}-1\right) n(a)+s} x\right)\right) \\
& \leq \alpha\left(b_{k_{0}}, b_{k_{0}}, b_{k_{0}},(M+1) b_{k_{0}},(M+1) b_{k_{0}}\right) \leq \gamma\left(b_{k_{0}}\right)<b_{k_{0}},
\end{aligned}
$$

which is a contradiction. This proves that

$$
b_{k} \leq b_{k-1} \quad \text { for all } k \geq 1 .
$$

Repeating the previous argument, for all $k \in \mathbb{N}$,

$$
\begin{aligned}
b_{k}= & q\left(a, T^{k n(a)+s} x\right)=q\left(T^{n(a)} a, T^{n(a)} T^{(k-1) n(a)+s} x\right) \\
\leq & \alpha\left(q\left(a, T^{(k-1) n(a)+s} x\right), q\left(a, T^{n(a)} a\right), q\left(a, T^{n(a)} T^{(k-1) n(a)+s} x\right),\right. \\
& \left.\quad q\left(T^{n(a)} a, T^{(k-1) n(a)+s} x\right), q\left(T^{n(a)} T^{(k-1) n(a)+s} x, T^{(k-1) n(a)+s} x\right)\right) \\
\leq & \alpha\left(b_{k-1}, 0, q\left(a, T^{k n(a)+s} x\right),\right. \\
& \left.\quad q\left(a, T^{(k-1) n(a)+s} x\right), q\left(T^{k n(a)+s} x, T^{(k-1) n(a)+s} x\right)\right) \\
= & \alpha\left(b_{k-1}, 0, b_{k}, b_{k-1}, q\left(T^{k n(a)+s} x, T^{(k-1) n(a)+s} x\right)\right)
\end{aligned}
$$

where

$$
\begin{aligned}
& q\left(T^{k n(a)+s} x, T^{(k-1) n(a)+s} x\right) \leq q\left(T^{k n(a)+s} x, a\right)+q\left(a, T^{(k-1) n(a)+s} x\right) \\
& \quad \leq M q\left(a, T^{k n(a)+s} x\right)+q\left(a, T^{(k-1) n(a)+s} x\right)=M b_{k}+b_{k-1} \leq(M+1) b_{k-1} .
\end{aligned}
$$

Thus,

$$
\begin{aligned}
b_{k} & \leq \alpha\left(b_{k-1}, 0, b_{k}, b_{k-1}, q\left(T^{k n(a)+s} x, T^{(k-1) n(a)+s} x\right)\right) \\
& \leq \alpha\left(b_{k-1}, b_{k-1}, b_{k},(M+1) b_{k-1},(M+1) b_{k-1}\right) \leq \gamma\left(b_{k-1}\right) .
\end{aligned}
$$

As $\gamma$ is nondecreasing,

$$
b_{k} \leq \gamma\left(b_{k-1}\right) \leq \gamma^{2}\left(b_{k-2}\right) \leq \ldots \leq \gamma^{k}\left(b_{0}\right)=\gamma^{k}\left(q\left(a, T^{s} x\right)\right) .
$$


Since $a, x$ and $s$ are fixed, then property $\left(\mathcal{P}_{4}\right)$ implies that $\left\{b_{k}\right\} \rightarrow 0$, that is

$$
\left\{q\left(a, T^{k n(a)+s} x\right)\right\} \rightarrow 0 .
$$

Varying $s \in\{0,1,2, \ldots, n(a)-1\}$, we conclude that Step 12 holds.

Step 13. We claim that, for each $x \in X$, we have that $\lim _{k \rightarrow \infty} q\left(T^{k} x, a\right)=0$.

This step follows from Step 12 and from item 4 of Lemma 3.3. Joining Steps 12 and 13, we have proved that $\left\{T^{k} x\right\} \rightarrow a$ for all $x \in X$.

Step 14. We shall show that $T^{n(a)}$ is continuous at a.

To prove this assertion, we take an arbitrary sequence $\left\{y_{k}\right\} \subseteq X$ that converges to $a$, that is,

$$
\lim _{k \rightarrow \infty} q\left(y_{k}, a\right)=\lim _{k \rightarrow \infty} q\left(a, y_{k}\right)=0
$$

Let show that

$$
q\left(a, T^{n(a)} y_{k}\right) \leq q\left(a, y_{k}\right) \quad \text { for all } k \in \mathbb{N}
$$

by contradiction. Assume that there exists some $k \in \mathbb{N}$ such that $q\left(a, T^{n(a)} y_{k}\right)>q\left(a, y_{k}\right)$. Again by $(3)$, we have that

$$
\begin{aligned}
& q\left(a, T^{n(a)} y_{k}\right)=q\left(T^{n(a)} a, T^{n(a)} y_{k}\right) \\
& \quad \leq \alpha\left(q\left(a, y_{k}\right), q\left(a, T^{n(a)} a\right), q\left(a, T^{n(a)} y_{k}\right), q\left(T^{n(a)} a, y_{k}\right), q\left(T^{n(a)} y_{k}, y_{k}\right)\right) \\
& \quad \leq \alpha\left(q\left(a, y_{k}\right), 0, q\left(a, T^{n(a)} y_{k}\right), q\left(a, y_{k}\right), q\left(T^{n(a)} y_{k}, y_{k}\right)\right) .
\end{aligned}
$$

Since

$$
\begin{aligned}
q\left(T^{n(a)} y_{k}, y_{k}\right) & \leq q\left(T^{n(a)} y_{k}, a\right)+q\left(a, y_{k}\right) \\
& \leq M q\left(a, T^{n(a)} y_{k}\right)+q\left(a, y_{k}\right) \leq(M+1) q\left(a, T^{n(a)} y_{k}\right),
\end{aligned}
$$

therefore

$$
\begin{aligned}
q\left(a, T^{n(a)} y_{k}\right) \leq & \alpha\left(q\left(a, y_{k}\right), 0, q\left(a, T^{n(a)} y_{k}\right), q\left(a, y_{k}\right), q\left(T^{n(a)} y_{k}, y_{k}\right)\right) \\
\leq & \alpha\left(q\left(a, T^{n(a)} y_{k}\right), q\left(a, T^{n(a)} y_{k}\right), q\left(a, T^{n(a)} y_{k}\right)\right. \\
& \left.(M+1) q\left(a, T^{n(a)} y_{k}\right),(M+1) q\left(a, T^{n(a)} y_{k}\right)\right) \\
\leq & \gamma\left(q\left(a, T^{n(a)} y_{k}\right)\right)<q\left(a, T^{n(a)} y_{k}\right),
\end{aligned}
$$

which is a contradiction. As a consequence, (20) holds, and by (19), $\left\{q\left(a, T^{n(a)} y_{k}\right)\right\} \rightarrow 0$. Moreover, as $q\left(T^{n(a)} y_{k}, a\right) \leq M q\left(a, T^{n(a)} y_{k}\right)$ for all $k \in \mathbb{N}$, then also $\left\{q\left(T^{n(a)} y_{k}, a\right)\right\} \rightarrow 0$. Therefore, $\left\{T^{n(a)} y_{k}\right\} \rightarrow a=T^{n(a)} a$, which means that $T^{n(a)}$ is continuous at $x=a$. This finishes the proof. 
Corollary 3.1. Let $(X, q)$ be a complete $M$-symmetric quasi-metric space, let $T: X \rightarrow X$ be a mapping and let $\varphi \in \mathcal{F}_{\text {Mat }}$ be a Matkowski function. Assume that, for each $x \in X$, there is a positive integer $n=n(x)$ such that

$$
\text { for all } y \in X, \quad q\left(T^{n(x)} x, T^{n(x)} y\right) \leq \varphi(q(x, y)) .
$$

Then $T$ has a unique fixed point $a \in X$. Moreover, for each $x \in X$, we have that $\lim _{k \rightarrow \infty} T^{k} x=a$ and $T^{n(a)}$ is continuous at $a$.

Proof. Given $\varphi \in \mathcal{F}_{\text {Mat }}$, let define $\alpha_{\varphi}:[0, \infty)^{5} \rightarrow[0, \infty)$ for all $t_{1}, t_{2}, t_{3}, t_{4}, t_{5} \in$ $[0, \infty)$ by

$$
\alpha_{\varphi}\left(t_{1}, t_{2}, t_{3}, t_{4}, t_{5}\right)=\varphi\left(t_{1}\right) .
$$

Then $\alpha_{\varphi}$ is nondecreasing on each argument and

$$
\alpha_{\varphi}(t, t, t,(M+1) t,(M+1) t)=\varphi(t) .
$$

Then $\left(\alpha_{\varphi}, \varphi, M\right)$ is a Matkowski's triple and

$$
\begin{aligned}
& \quad q\left(T^{n(x)} x, T^{n(x)} y\right) \leq \varphi(q(x, y)) \\
& \quad=\alpha_{\varphi}\left(q(x, y), q\left(x, T^{n(x)} x\right), q\left(x, T^{n(x)} y\right), q\left(T^{n(x)} x, y\right), q\left(T^{n(x)} y, y\right)\right) .
\end{aligned}
$$

This means that Theorem 3.1 is applicable.

In the following result, the integer $n=n(x)$ is constant.

Corollary 3.2. Let $(X, q)$ be a complete $M$-symmetric quasi-metric space and let $T: X \rightarrow X$ be a mapping. Suppose that there exists a Matkowski's triple $(\alpha, \gamma, M)$ and a positive integer number $n$ such that, for all $x, y \in X$,

$$
q\left(T^{n} x, T^{n} y\right) \leq \alpha\left(q(x, y), q\left(x, T^{n} x\right), q\left(x, T^{n} y\right), q\left(T^{n} x, y\right), q\left(T^{n} y, y\right)\right)
$$

Then $T$ has a unique fixed point $a \in X$. Furthermore, for each $x \in X$, $\lim _{k \rightarrow \infty} T^{k} x=a$ and $T^{n}$ is continuous at $a$.

If we take $\lambda \in[0,1)$ and $\varphi_{\lambda}(t)=\lambda t$ for all $t \geq 0$, then $\varphi_{\lambda} \in \mathcal{F}_{\text {Mat }}$ and we get the following result.

Corollary 3.3. Let $(X, q)$ be a complete $M$-symmetric quasi-metric space, let $T: X \rightarrow X$ be a mapping and let $\lambda \in[0,1)$. Assume that, for each $x \in X$, there is a positive integer $n=n(x)$ such that

$$
\text { for all } y \in X, \quad q\left(T^{n(x)} x, T^{n(x)} y\right) \leq \lambda q(x, y) .
$$

Then $T$ has a unique fixed point $a \in X$. Moreover, for each $x \in X$, we have that $\lim _{k \rightarrow \infty} T^{k} x=a$ and $T^{n(a)}$ is continuous at $a$. 
If we take $\varphi(t)=t /(1+t)$ for all $t \geq 0$, then $\varphi \in \mathcal{F}_{\text {Mat }}$ and we get the following result.

Corollary 3.4. Let $(X, q)$ be a complete $M$-symmetric quasi-metric space and let $T: X \rightarrow X$ be a mapping. Assume that, for each $x \in X$, there is a positive integer $n=n(x)$ such that

$$
\text { for all } y \in X, \quad q\left(T^{n(x)} x, T^{n(x)} y\right) \leq \frac{q(x, y)}{1+q(x, y)} .
$$

Then $T$ has a unique fixed point $a \in X$. Moreover, for each $x \in X$, we have that $\lim _{k \rightarrow \infty} T^{k} x=a$ and $T^{n(a)}$ is continuous at $a$.

\subsection{The Matkowski's theorem using a symmetric contractivity con- dition on quasi-metric spaces}

In this subsection, we show how it is possible to consider a version of Theorem 1.1 on quasi metric spaces using a symmetric contractivity condition, like in the following result.

Theorem 3.2. Let $(X, q)$ be a complete quasi-metric space, let $T: X \rightarrow X$ be a mapping and let $\varphi \in \mathcal{F}_{\text {Mat }}$ be a Matkowski function. Assume that, for each $x \in X$, there is a positive integer $n=n(x)$ such that

$$
\begin{aligned}
& \text { for all } y \in X, \\
& \qquad \begin{array}{l}
q\left(T^{n(x)} x, T^{n(x)} y\right) \leq \varphi(q(x, y)) \quad \text { and } \\
\\
\quad\left(T^{n(x)} y, T^{n(x)} x\right) \leq \varphi(q(y, x)) .
\end{array}
\end{aligned}
$$

Then $T$ has a unique fixed point $a \in X$. Moreover, for each $x \in X$, we have that $\lim _{k \rightarrow \infty} T^{k} x=a$ and $T^{n(a)}$ is continuous at $a$.

Although Theorem 3.2 seems to be an extension of Theorem 1.1, actually, it is not a true generalization. In fact, we are going to show that Theorem 1.1 and Theorem 3.2 are, indeed, equivalent.

Lemma 3.4. Theorem 1.1 follows from Theorem 3.2.

Proof. If $q$ is a metric on $X$, then both conditions (22) and (23) are equivalent to (2). Then, if we assume that Theorem 3.2 holds, it is evident that Theorem 1.1 also holds.

Lemma 3.5. Theorem 3.2 follows from Theorem 1.1. 
Proof. Assume that Theorem 1.1 holds, and we are going to show that Theorem 3.2 also holds. Let $(X, q)$ be a complete quasi-metric space, let $T: X \rightarrow X$ be a mapping and let $\varphi \in \mathcal{F}_{\text {Mat }}$ be a Matkowski function. Assume that, for each $x \in X$, there is a positive integer $n=n(x)$ such that (22)-(23) holds. Let define $d_{q}: X \times X \rightarrow[0, \infty)$ by

$$
d_{q}(x, y)=\max \{q(x, y), q(y, x)\} \quad \text { for all } x, y \in X .
$$

As $(X, q)$ is a complete quasi-metric space, it is well-know that $d_{q}$ is a complete metric on $X$. Furthermore, given $x \in X$, let $n(x) \in \mathbb{N}$ be such that (22)-(23) holds. Then, taking into account that $\varphi$ is a nondecreasing function, we have, for all $y \in X$,

$$
\begin{aligned}
d_{q}\left(T^{n(x)} x, T^{n(x)} y\right) & =\max \left\{q\left(T^{n(x)} x, T^{n(x)} y\right), q\left(T^{n(x)} y, T^{n(x)} x\right)\right\} \\
& \leq \max \{\varphi(q(x, y)), \varphi(q(y, x))\} \\
& =\varphi(\max \{q(x, y), q(y, x)\}) \\
& =\varphi\left(d_{q}(x, y)\right) .
\end{aligned}
$$

Hence, $T$ verifies the contractivity condition of Theorem 1.1. Such theorem guarantees that $T$ has a unique fixed point $a \in X$ and that $\lim _{k \rightarrow \infty} T^{k} x=a$ for each $x \in X$.

In our main theorems, we have used that $\varphi$ is a nondecreasing function satisfying $\left(\varphi_{3}\right)=\left(\mathcal{P}_{4}\right)$ and $\left(\varphi_{6}\right)=\left(\mathcal{P}_{3}\right)$. By Corollary 2.1, we can replace these conditions by another ones.

Corollary 3.5. Corollary 3.1 and Theorem 3.2 also hold if $\varphi$ is a nondecreasing function satisfying $\left(\varphi_{4}\right)$ and $\left(\varphi_{5}\right)$.

If we take $\lambda \in[0,1)$ and $\varphi_{\lambda}(t)=\lambda t$ for all $t \geq 0$, then $\varphi_{\lambda} \in \mathcal{F}_{\text {Mat }}$ and we get the following result.

Corollary 3.6. Let $(X, q)$ be a complete quasi-metric space, let $T: X \rightarrow X$ be a mapping and let $\lambda \in[0,1)$. Assume that, for each $x \in X$, there is a positive integer $n=n(x)$ such that

$$
\begin{aligned}
& \text { for all } y \in X \\
& \qquad \begin{aligned}
q\left(T^{n(x)} x, T^{n(x)} y\right) \leq \lambda q(x, y) \quad \text { and } \\
\\
q\left(T^{n(x)} y, T^{n(x)} x\right) \leq \lambda q(y, x) .
\end{aligned}
\end{aligned}
$$

Then $T$ has a unique fixed point $a \in X$. Moreover, for each $x \in X$, we have that $\lim _{k \rightarrow \infty} T^{k} x=a$ and $T^{n(a)}$ is continuous at $a$. 
If we take $\varphi(t)=t /(1+t)$ for all $t \geq 0$, then $\varphi \in \mathcal{F}_{\text {Mat }}$ and we get the following result.

Corollary 3.7. Let $(X, q)$ be a complete quasi-metric space and let $T: X \rightarrow$ $X$ be a mapping. Assume that, for each $x \in X$, there is a positive integer $n=n(x)$ such that

$$
\begin{aligned}
& \text { for all } y \in X, \\
& \qquad \begin{aligned}
q\left(T^{n(x)} x, T^{n(x)} y\right) & \leq \frac{q(x, y)}{1+q(x, y)} \quad \text { and } \\
& q\left(T^{n(x)} y, T^{n(x)} x\right) \leq \frac{q(y, x)}{1+q(y, x)} .
\end{aligned}
\end{aligned}
$$

Then $T$ has a unique fixed point $a \in X$. Moreover, for each $x \in X$, we have that $\lim _{k \rightarrow \infty} T^{k} x=a$ and $T^{n(a)}$ is continuous at $a$.

\section{Consequences: Fixed Point Results on $G$-Metric Spaces}

In this section, we particularize the previous results to the setting of $G$-metric spaces, and we show that some existing fixed point results in the context of $G$ metric spaces can be easily deduced from our main theorems. For the sake of completeness, we collect here some definitions and basic result about $G$-metric spaces (for more details, see e.g. [3]-[18]).

In 2003, Mustafa and Sims [12] proved that most of the claims concerning the topological properties of $D$-metrics were incorrect. In order to repair these drawbacks, they gave a more appropriate notion of generalized metrics, called G-metrics.

Definition 4.1. (Mustafa and Sims [12]) $A G$-metric space is a pair $(X, G)$ where $X$ is a nonempty set and $G: X \times X \times X \rightarrow[0, \infty)$ is a function such that, for all $x, y, z, a \in X$, the following conditions are fulfilled:

$\left(G_{1}\right) \quad G(x, y, z)=0 \quad$ if $x=y=z$;

$\left(G_{2}\right) \quad G(x, x, y)>0 \quad$ for all $x, y \in X$ with $x \neq y$;

$\left(G_{3}\right) \quad G(x, x, y) \leq G(x, y, z)$ for all $x, y, z \in X$ with $z \neq y$;

$\left(G_{4}\right) \quad G(x, y, z)=G(x, z, y)=G(y, z, x)=\ldots$ (symmetry in all three variables);

$\left(G_{5}\right) \quad G(x, y, z) \leq G(x, a, a)+G(a, y, z) \quad$ (rectangle inequality).

In such a case, the function $G$ is called a $G$-metric on $X$. 
Example 4.1. If $X$ is a non-empty subset of $\mathbb{R}$, then the function $G: X \times$ $X \times X \rightarrow[0, \infty)$, given by

$$
G(x, y, z)=|x-y|+|x-z|+|y-z| \quad \text { for all } x, y, z \in X,
$$

is a $G$-metric on $X$.

One of the most useful properties of $G$-metrics is the following one.

Lemma 4.1. If $(X, G)$ is a $G$-metric space, then

$$
G(x, y, y) \leq 2 G(y, x, x) \quad \text { for all } x, y \in X .
$$

Definition 4.2. Let $(X, G)$ be a $G$-metric space, let $x \in X$ be a point and let $\left\{x_{m}\right\} \subseteq X$ be a sequence. We say that:

- $\left\{x_{m}\right\} G$-converges to $x$, and we write $\left\{x_{n}\right\} \stackrel{G}{\longrightarrow} x$ or $\left\{x_{n}\right\} \rightarrow x$, if $\lim _{m, m^{\prime} \rightarrow \infty} G\left(x_{m}, x_{m^{\prime}}, x\right)=0$, that is, for all $\varepsilon>0$ there exists $m_{0} \in \mathbb{N}$ verifying that $G\left(x_{m}, x_{m^{\prime}}, x\right)<\varepsilon$ for all $m, m^{\prime} \in \mathbb{N}$ such that $m, m^{\prime} \geq m_{0}$ (in such a case, $x$ if the $G$-limit of $\left\{x_{m}\right\}$ );

- $\left\{x_{m}\right\}$ is $G$-Cauchy if $\lim _{m, m^{\prime}, m^{\prime \prime} \rightarrow \infty} G\left(x_{m}, x_{m^{\prime}}, x_{m^{\prime \prime}}\right)=0$, that is, for all $\varepsilon>0$ there exists $m_{0} \in \mathbb{N}$ verifying that $G\left(x_{m}, x_{m^{\prime}}, x_{m^{\prime \prime}}\right)<\varepsilon$ for all $m, m^{\prime}, m^{\prime \prime} \in \mathbb{N}$ such that $m, m^{\prime}, m^{\prime \prime} \geq m_{0}$.

- $(X, G)$ is complete if every $G$-Cauchy sequence in $X$ is $G$-convergent in $X$.

Theorem 4.1. Let $(X, G)$ be a $G$-metric space and let $q_{G}: X \times X \rightarrow[0, \infty)$ be the function defined by $q_{G}(x, y)=G(x, y, y)$ for all $x, y \in X$. Then:

1. $\left(X, q_{G}\right)$ is a 2-symmetric quasi-metric space;

2. $\left\{x_{n}\right\} \subseteq X$ is $G$-convergent to $x \in X$ if, and only if, $\left\{x_{n}\right\}$ is convergent to $x$ in $\left(X, q_{G}\right)$;

3. $\left\{x_{n}\right\} \subseteq X$ is G-Cauchy if, and only if, $\left\{x_{n}\right\}$ is Cauchy in $\left(X, q_{G}\right)$;

4. $(X, G)$ is $G$-complete if, and only if, $\left(X, q_{G}\right)$ is complete.

Lemma 4.2. The previous theorem also holds if we replace $q_{G}$ by $q_{G}^{\prime}$, defined by $q_{G}^{\prime}(x, y)=G(x, x, y)$ for all $x, y \in X$.

The following one is the particularization of Theorem 3.1 to quasi-metric spaces of the form $\left(X, q_{G}\right)$ given in Theorem 4.1. 
Corollary 4.1. Let $(X, G)$ be a complete $G$-metric space and let $T: X \rightarrow X$ be a mapping. Suppose that there exists a Matkowski's triple $(\alpha, \gamma, 2)$ verifying the following property:

- for every $x \in X$, there is a positive integer $n=n(x)$ such that, for all $y \in X$,

$$
\begin{array}{r}
G\left(T^{n(x)} x, T^{n(x)} y, T^{n(x)} y\right) \leq \alpha\left(G(x, y, y), G\left(x, T^{n(x)} x, T^{n(x)} x\right),\right. \\
\left.G\left(x, T^{n(x)} y, T^{n(x)} y\right), G\left(T^{n(x)} x, y, y\right), G\left(T^{n(x)} y, y, y\right)\right) .
\end{array}
$$

Then $T$ has a unique fixed point $a \in X$. Furthermore, for each $x \in X$, $\lim _{k \rightarrow \infty} T^{k} x=a$ and $T^{n(a)}$ is continuous at $a$.

The same result using $q_{G}^{\prime}$ as in Lemma 4.2 is given in the following statement.

Corollary 4.2. Let $(X, G)$ be a complete $G$-metric space and let $T: X \rightarrow X$ be a mapping. Suppose that there exists a Matkowski's triple $(\alpha, \gamma, 2)$ verifying the following property:

- for every $x \in X$, there is a positive integer $n=n(x)$ such that, for all $y \in X$,

$$
\begin{aligned}
& G\left(T^{n(x)} x, T^{n(x)} x, T^{n(x)} y\right) \leq \alpha\left(G(x, x, y), G\left(x, x, T^{n(x)} x\right)\right. \\
&\left.G\left(x, x, T^{n(x)} y\right), G\left(T^{n(x)} x, T^{n(x)} x, y\right), G\left(T^{n(x)} y, T^{n(x)} y, y\right)\right) .
\end{aligned}
$$

Then $T$ has a unique fixed point $a \in X$. Furthermore, for each $x \in X$, $\lim _{k \rightarrow \infty} T^{k} x=a$ and $T^{n(a)}$ is continuous at $a$.

As a consequence, the main result in [2] can be seen as a simple consequence of the previous results.

Theorem 4.2. Theorem 1.2 immediately follows from Corollary 3.1.

Proof. It is sufficient to take $q_{G}(x, y)=G(x, x, y)$ for all $x, y \in X$ in Corollary 3.1 together with Theorem 4.1. Notice that the conditions $\left(\varphi_{3}\right) \&\left(\varphi_{6}\right)$ and $\left(\varphi_{4}\right) \&\left(\varphi_{5}\right)$ are equivalent due to Corollary 2.1.

\section{Competing interests}

The authors declare that there is no conflict of interests regarding the publication of this article. 


\section{Authors' contributions}

All authors contributed equally and significantly in writing this article. All authors read and approved the final manuscript.

\section{Acknowledgements}

The second author has been partially supported by Junta de Andalucía by project FQM-268 of the Andalusian CICYE. The third author would like to extend his sincere appreciation to the Deanship of Scientific Research at King Saud University for its funding of this research through the Research Group Project no RGP-VPP-237. The third author extends his appreciation to Distinguished Scientist Fellowship Program (DSFP) at King Saud University (Saudi Arabia).

\section{References}

[1] Matkowski, J: Fixed point theorems for mappings with a contractive iterate at a point. Proc. Amer. Math. Soc. 62, 344-348 (1997)

[2] Gajić, L, Stojaković, M: On mappings with $\varphi$-contractive iterate at a point on generalized metric spaces. Fixed Point Theory Appl. 2014, 2014:46

[3] Samet, B, Vetro, C, Vetro, F: Remarks on $G$-metric spaces. Intern. J. Anal. 2013, Article ID 917158 (2013)

[4] Jleli, M, Samet, B: Remarks on $G$-metric spaces and fixed point theorems. Fixed Point Theory Appl. 2012, 2012:210

[5] Roldán, A, Martínez-Moreno, J, Roldán, C, Karapınar, E: Some remarks on multidimensional fixed point theorems. Fixed Point Theory 15 (2014), No. 2, $545-558$.

[6] Alsulami, HH, Roldán-López-de-Hierro, AF, Karapınar, E, Radenović, S: Some Inevitable Remarks on "Tripled Fixed Point Theorems for Mixed Monotone Kannan Type Contractive Mappings" . J. Appl. Math 2014, Article ID 392301, 7 pages.

[7] Al-Mezel, SA, Alsulami, HH, Karapınar, E, Roldán-López-de-Hierro, AF: Discussion on "Multidimensional coincidence points" via recent publications. Abstr. Appl. Anal. 2014, Article ID 287492, 13 pages.

[8] Erhan, IM, Karapınar, E, Roldán-López-de-Hierro, AF, Shahzad, N: Remarks on "Coupled coincidence point results for a generalized compatible pair with applications", Fixed Point Theory Appl., to appear.

[9] Agarwal, RP, Karapınar, E, Roldán-López-de-Hierro, AF: Fixed point theorems in quasi-metric spaces and applications to multidimensional fixed point theorems on $G$-metric spaces. J. Nonlinear Convex Anal., in press. 
[10] Bilgili, N, Karapınar, E, Samet, B: Generalized $\alpha-\psi$ - contractive mappings in quasi-metric spaces and related fixed point theorems. J. Ineq. Appl. 2014, 2014:36

[11] Aydi, H, Hadj-Amor, S, Karapınar, E: Some almost generalized $(\psi, \phi)$ contractions in $G$-metric spaces. Abstr. Appl. Anal. 2013, Article Id: 165420 (2013)

[12] Mustafa, Z, Sims, B: A new approach to generalized metric spaces. J. Nonlinear Convex Anal. 7, 289-297 (2006)

[13] Mustafa, Z, Sims, B: Fixed point theorems for contractive mappings in complete $G$-metric spaces. Fixed Point Theory Appl. 2009, Article ID 917175 (2009)

[14] Mustafa, Z: A new structure for generalized metric spaces with applications to fixed point theory, Ph.D. Thesis, The University of Newcastle, Australia, 2005.

[15] Alghamdi, MA, Karapınar, E: $G-\beta-\psi$-contractive type mappings and related fixed point theorems. J. Ineq. Appl. 2013, 2013:70

[16] Alghamdi, MA, Karapınar, E: $G-\beta-\psi$-contractive type mappings in $G$-metric spaces. Fixed Point Theory Appl. 2013, 2013:123

[17] Agarwal, RP, Karapinar, E: Remarks on some coupled fixed point theorems in $G$-metric spaces. Fixed Point Theory Appl. 2013, 2013:2

[18] Agarwal, RP, Karapınar, E: Further fixed point results on $G$-metric spaces. Fixed Point Theory Appl. 2013, 2013:154

Erdal Karapinar,

Department of Mathematics,

Atilim University,

06836, Incek, Ankara, Turkey.

Email: erdal.karapinar@atilim.edu.tr

Antonio-Francisco Roldán-López-de-Hierro,

Department of Quantitative Methods for Economics and Business,

Faculty of Economic and Business Sciences,

University of Granada,

Campus Universitario de La Cartuja, 18011, Granada, Spain.

Email: aroldan@ugr.es, afroldan@ujaen.es

Bessem Samet,

Department of Mathematics,

King Saud University, Saudi Arabia.

Email: bsamet@ksu.edu.sa 